\title{
Evolutionary patterns of asymmetric genitalia in the beetle tribe Cyclocephalini (Coleoptera: Scarabaeidae: Dynastinae)
}

\author{
Thijmen Breeschoten ${ }^{1,2,4}$, Daniel R. Clark ${ }^{3}$, Menno Schilthuizen ${ }^{1,2}$ \\ ${ }^{1}$ Character Evolution Group, Naturalis Biodiversity Center, Darwinweg 2, 2333 CR Leiden, The Netherlands \\ ${ }^{2}$ Institute Biology Leiden, Leiden University, Sylviusweg 72, 2333 BE Leiden, The Netherlands \\ ${ }^{3}$ Department of Biological Sciences, 537 Hubbard Hall, Wichita State University, Wichita, Kansas, 68588-0514, \\ USA \\ ${ }^{4}$ E-mail: T.Breeschoten@outlook.com
}

Key words: chirality, left-right asymmetry, micro-CT scanning, morphometrics, Procrustes distance

\begin{abstract}
The evolution of asymmetric genitalia is a common and recurrent phenomenon in a wide variety of insect taxa. However, little is understood about the evolution of left-right asymmetry in reproductive structures. Since a better knowledge of it could have an important impact on the study of genital evolution, in the present study we investigate the phylogenetic and evolutionary patterns of asymmetric male genitalia in Cyclocephalini. We use a Procrustes distance based method for quantifying asymmetry. Analysis of 119 species belonging to 14 genera revealed a diverse array of asymmetries with a strong indication that asymmetries are more strongly developed in the terminal part of the aedeagus. Further, we find that asymmetries have evolved repeatedly within this small taxon. Micro-CT scans, a technique not employed before in studies of genital asymmetry, are made of several symmetric and asymmetric species. This reveals unexpected asymmetric sclerotised structures inside the otherwise symmetric aedeagus of Cyclocephala amazona, which underlines that asymmetries are not restricted to the exterior of the male genitalia but are also found internally.
\end{abstract}

\section{Contents}

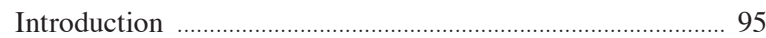

Material and methods ……………........................................... 97

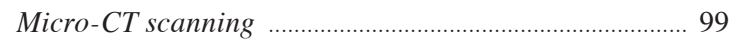

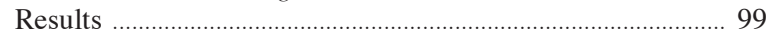

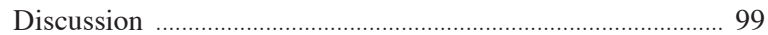

Acknowledgements .............................................................. 102

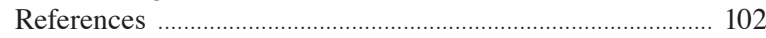

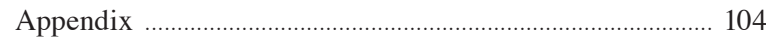

\section{Introduction}

Diversity and complexity among insect genitalia is immense (Leonard and Córdoba-Aguilar, 2010). This involves the species specificity that has been known and used by taxonomists for identification and classification.
Currently, several chief mechanisms are recognized as potentially being responsible for this vast diversity (Schilthuizen, 2003; Eberhard, 2010). First, sexual selection by cryptic female choice may drive the evolution of exaggerated structures on male genitalia (Eberhard, 1985). Second, sperm competition, the post-copulatory sexual selection between males inside the females' reproductive tract is possibly important in creating the diversity in male genital morphology (Parker, 1970). This mechanism appears to be involved in, for example, males of the mealworm Tenebrio molitor Linnaeus, 1758, which use spines on their aedeagi to scour out rival sperm from the spermatheca (Gage, 1992). Finally, male-female conflict, the antagonistic coevolution between the sexes, may lead to the diverse and anatomically complex genitalia seen at species level (Schilthuizen, 2003). However, these mechanisms are not necessarily mutually exclusive (Eberhard, 2004, 2006). Possibly, different aspects of male genital morphology can be the result of different mechanisms having acted at different moments in the evolution of a lineage leading to the accumulated genital complexity and diversity (Werner and Simmons, 2008).

Asymmetry is one of the aspects of shape complexity that is common among Insecta (Schilthuizen, 2013). Symmetric genitalia are the default state in most insect groups, but many insect taxa with asymmetric genitalia are known. Huber et al. (2007) systematically reviewed known cases of asymmetry in insects and found that genital asymmetry in insects 'originated a few times within Dermaptera, Neuropteridae, Plecoptera and Siphonaptera; several times within Heteroptera, Homoptera, Psocodea, Trichoptera; and many times within Coleoptera, Diptera and ditrysian Lepidoptera'.

This commonness is surprising since symmetry is generally thought to be favoured in sexual signalling 
(Møller and Pomiankowski, 1993; Swaddle and Cuthill, 1994; van Dongen, 2006). Therefore, it is striking that populations have been able to cross this presumed adaptive valley and evolve strong asymmetries so frequently. Huber et al. (2007) proposed several hypotheses for the evolution of asymmetric genitalia, namely (i) mechanical compensation for a change in mating position; (ii) functional specialisation of left and right side; (iii) resource conservation by one-sided reduction; (iv) functional constraints; $(v)$ more efficient packing; and (vi) intersexual arms races. They concluded that, while certain of these hypotheses may be supported in particular narrowly defined taxa, only the first (compensation for changes in mating position) fits with the general patterns of asymmetry across all Insecta. However, it is not likely that the evolution of mating positions is the most important factor leading to asymmetric genitalia within such small taxa as the Cyclocephalini, since most Scarabaeoidae members (Passalidae being one notable exception) show the same mating position; yet both symmetry and asymmetry are present in the male genitalia of many scarabaeoid taxa (Schilthuizen, unpublished data).

Understanding the evolution of left-right asymmetry could have an important impact on our knowledge of the evolution of development and the selection for morphological novelties as a reaction to behavioural changes (Huber et al., 2007; Schilthuizen, 2013). A combination of morphometrics with phylogenetics may constitute the first step towards increasing our understanding of the evolution of asymmetry in reproductive organs. Here, we apply this approach to the rhinoceros beetle tribe Cyclocephalini (Coleoptera: Scarabaeidae: Dynastinae). This taxon contains 15 genera and approximately 500 species (Endrödi, 1985; Jameson et al.,
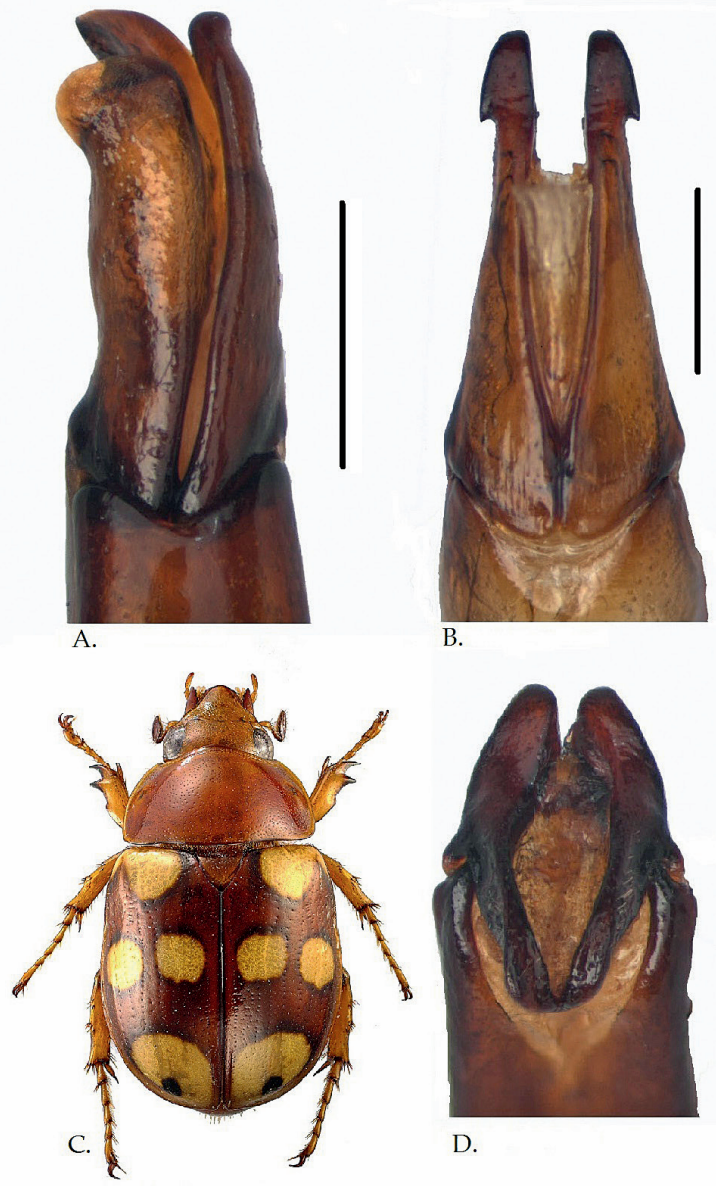

B.

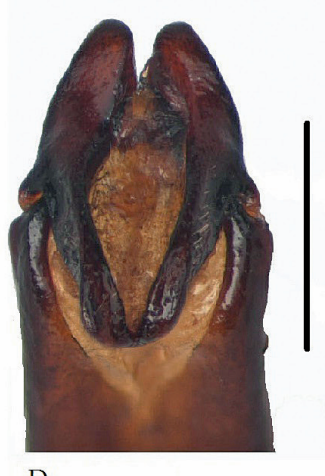

D.

Fig. 1. Dorsal view of (A) extremely asymmetric parameres of C. brittoni, (B) symmetric parameres of C.pubescens, (C) habitus of $C$. ocellata, impression of a Cyclocephalini representative; no asymmetry data is obtained of this species (Photo: J.H. Yvinec), and (D) slightly asymmetric parameres of $C$. forsteri $($ scale bar $=1 \mathrm{~mm})$.
Fig. 2. Distribution of species with asymmetric genitalia in Cyclocephalini, showing the total number of species per genus (black) and the number of species with asymmetric genitalia per genus (grey). Number of species with asymmetric aedeagi in Peltonotus is set to 25. Males are known in only 20 of the 25 species, but the expectation is that males in all species show asymmetric genitalia.

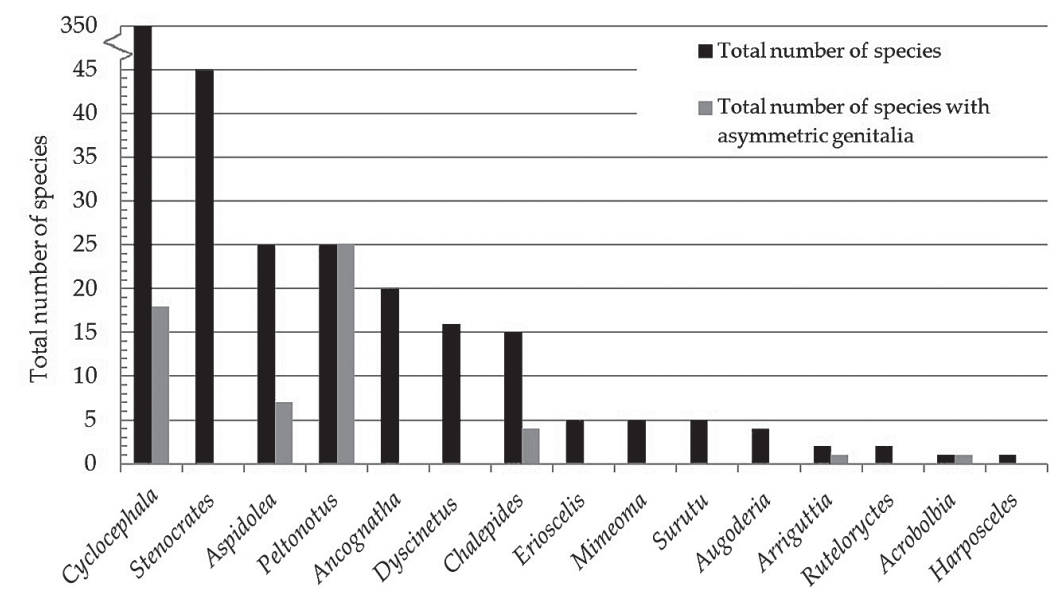


2002; Jameson and Wada, 2009). All but two genera are distributed in the New World. Although the tribe is placed in the rhinoceros beetle subfamily, members of which are recognized by having one or several horns on the head and/or thorax, Cyclocephalini mostly lack such adornments. This may be why this group in the past was of less interest to collectors, behavioural biologists studying sexual selection, and others. Recently, this changed as Cyclocephalini beetles were found to be important pollinators of palms, lilies, guava trees, aroids, and magnolia trees (Gibernau et al., 1999; Krell et al., 2003; Ratcliffe and Cave, 2008) and some species' larvae have been recognized as significant pests of turf grass and agricultural crops (Ratcliffe and Paulsen, 2008; Clark, 2011).

In Cyclocephalini, approximately 50 species distributed over six genera show asymmetric male genitalia. The asymmetry varies from small differences between lateral teeth to extreme sideward curvatures of 45 degrees (Fig. 1). Only two genera, Peltonotus and Acrobolbia, consist entirely of species having asymmetric genitalia, the latter consisting of only one species (Fig. 2). The available number of species and the widespread occurrence of asymmetric aedeagi make Cyclocephalini an ideal tribe for this type of research.

\section{Material and methods}

In total we measured the degree of asymmetry in 119 species belonging to 14 genera in the Cyclocephalini. Of these, 101 species belonging to 13 genera were taken from the collection of Naturalis Biodiversity Center. The remaining 18 species (from two genera) were assessed by using the photographs in Jameson et al. (2002), Jameson and Wada (2004), and Jameson and Jakl (2009). An overview of all analyzed material is given in the Appendix.

Collection specimens were treated as follows. The abdomen of one male specimen of each species was softened in water of $80^{\circ} \mathrm{C}$ for 30 minutes, after which the aedeagus was dissected from the body cavity and placed for 10-12 hours in $10 \% \mathrm{KOH}$ (room temperature, $21^{\circ} \mathrm{C}$ ) to remove membranes and to increase contrast. Then, each aedeagus was glued onto a piece of cardboard, and positioned in such a way that the phallobase and parameres were clearly visible. Separate pictures were made of both the phallobase and parameres using a Zeiss Discovery V12 Stereo, with an AxioCam MRc 5 camera built on top (Carl Zeiss MicroImaging, Göttingen, Germany). Stacking of the photographs was performed with AxioVision Rel. 4.8.2 (Carl Zeiss MicroImaging, Göttingen, Germany). A mesh of $100 \times 100$ pixels was placed on the photographs using Photoshop Elements 7 (Adobe Systems, Mountain View, CA). Furthermore, the pictures were rotated into an exactly vertical position using a straight line through the structure which was rotated in a right angle with the horizontal lines of the grid, overall brightness and contrast were adjusted and a mirror image of the original was created using the same program.

With tpsDig 2.16 (Rohlf, 2010), landmarks were placed using a standardized method with the help of the gridlines (Fig. 3). On both the original and mirrored images of the phallobase, three pairs of landmarks were placed at the top of the structure at the intersection of the three grid lines, the following three pairs were placed at the intersection of the lowest three gridlines, and the last two landmarks were placed on the extremities of a drawn line in order to define the axis. On the original and mirrored images of the parameres, the first four landmark pairs were placed at the intersection of the four highest gridlines, a fifth pair was placed on the inside of the two parameres, two pairs were placed above the widest part of the parameres, and another pair of landmarks was placed at the intersection of the lowest gridline. Again, the last two landmarks were placed on the extremities of the axis line.

A Procrustes superimposition was performed between the original and the mirror image of each specimen and the Procrustes distance (PD) was calculated using Coordgen7a from the IMP series (Sheets, 2011). This PD served as 'asymmetry value', showing the overall degree of asymmetry. We should point out that this method is suited for structures showing asymmetry on the outlines only; other types of asymmetry, e.g., in the toothlike-connection points of the parameres, proximal of the phallobase may only be quantified using Fourier analyses rather than 'stand-alone' landmarks. Two control groups were created. Control group 1 consisted of five different computer-generated perfectly symmetric objects using Paint that underwent the same procedure as the aedeagi (grid placement, image mirroring, landmark placement and PD calculation) with 10 repetitions, thus providing a control for the correct placement of landmarks. Control group 2 consisted of five different, but perfectly symmetric, plastic toothbrushes that underwent the same procedure as the aedeagi (grid placement, image mirroring, landmark placement and PD calculation) with a repetition of 10 times, controlling for the correct positioning of the objects during photographing and the correct placement 


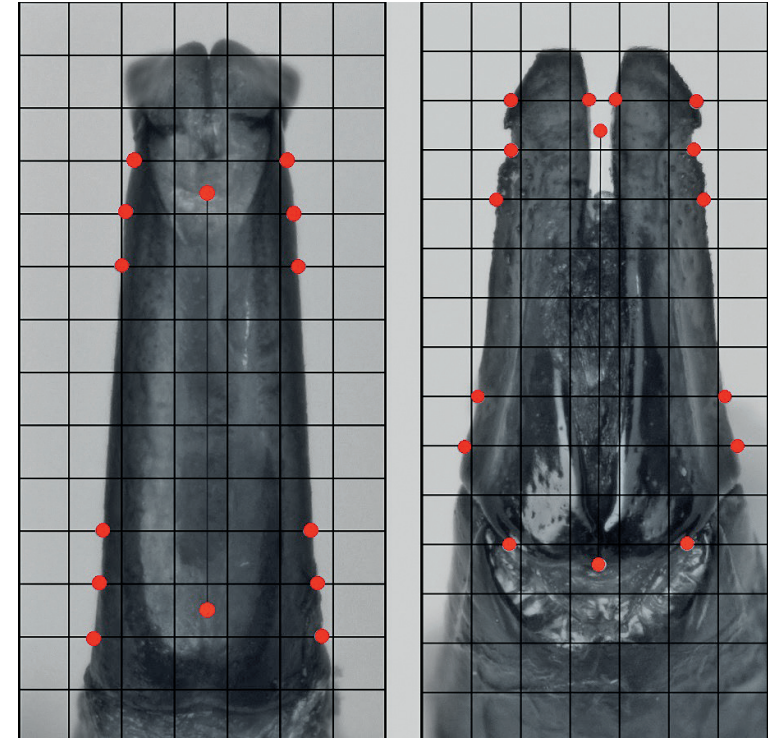

Fig. 3. Landmark positions using 16 landmarks for parameres and 14 landmarks for phallobases. The gridlines helped in placing the landmarks in a standardized way on both the original and mirrored pictures (not shown).

of landmarks. Apparent deviation from symmetry due to errors in object manipulation and landmark placement was evaluated by documenting the calculated PD values for the two control groups. The result is shown in Fig. 4 A.

The duplicated pooled mean of the PD values for the control groups, viz. 0.0157, was considered to span the expected PD range for perfectly symmetric objects. Therefore, this value was used for categorising the PD values for the aedeagi over same-sized character state bins. This way, we created different asymmetry groups ranging from 1 (symmetric) to 18 (highly asymmetric).

A phylogenetic reconstruction for the Cyclocephalini was produced as follows. We obtained a character matrix for 48 species and 77 adult morphological characters from Clark (2011). We removed character 71, dealing with the symmetric state of the male genitalia in order to avoid circularity. Furthermore, we removed from this data set all species for which we did not have PD values. Then, we obtained data for the same morphological characters for six additional species. They are Aspidolea boulardi Dechambre, 1979, A. cognata Höhne, 1922, Cyclocephala brittoni Endrödi, 1964, C. cartwrighti Endrödi, 1964, C. forsteri Endrödi, 1963 and $C$. suturalis Ohaus, 1911. We also included one extra species of each genus for which Clark (2011) had initially analyzed only one species; hereby copying all character states except for the species specific PD values, ensuring a monophyletic genus. These are Erioscelis proba Sharp, 1877, Stenocrates carbunculus Prell, 1938, and Mimeoma maculata Burmeister, 1847. In total, we obtained a data set with 78 character and 44 Cyclocephalini species, plus Xyloryctes jamaicensis (Drury, 1773) as outgroup. Phylogenetic hypotheses were created using PAUP 4.0b10 (Swofford, 2001). The phylogeny was created using 1000 heuristic searches with random addition sequence. The characters were reweighted using the rescaled consistency index to
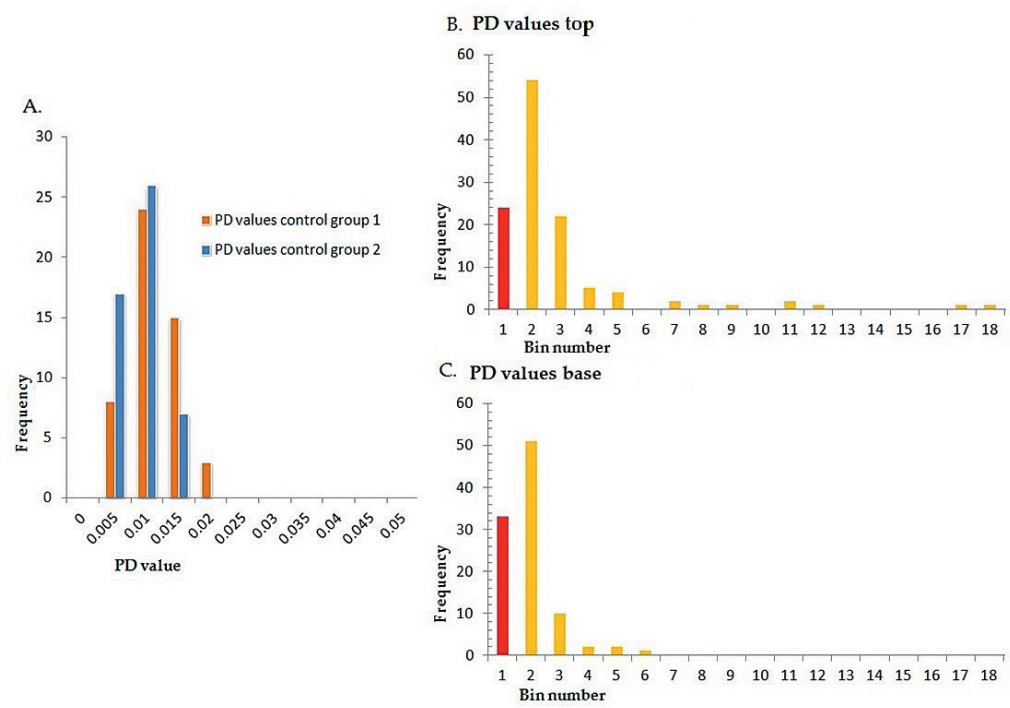

Fig. 4. Procrustes distance (PD) values (categorised with bin sizes of 0.005) of (A) control group 1 (orange; 50 calculations of five different computer-generated symmetric objects), and control group 2 (blue; 50 calculations of five different toothbrushes). (B) PD values of parameres (top) of 118 specimens of 118 species, and (C) PD values of phallobases (base) of 99 specimens of 99 species. PD was calculated using an unmanipulated and a mirrored photograph of the same structure of each specimen per species (see text). Bin size $(0.0157)$ is the duplicated pooled mean of the control groups showing the range of perfectly symmetric parameres and phallobases (red). Bin number equals the degree of asymmetry with a value of 1 considered to show perfect symmetry and values above 1 showing increasing asymmetry. 
optimize the phylogeny. A strict consensus was made over all optimal trees. A bootstrap analysis was run using a heuristic search with 100 replications. Values greater than $70 \%$ were considered to provide strong support for clades (Felsenstein, 1985). PD values were projected onto the phylogenetic tree using Mesquite 2.75 (Maddison and Maddison, 2011). The first two character states, ranging from 0 to 0.0331 , are kept blank on the phylogenies assuring that only asymmetric structures are visible.

A scatter plot of PD values of the parameres against those of the phallobases was made using $\mathrm{R}$ version 2.11.0 ( $\mathrm{R}$ development core team, 2010) and the correlation was tested for significance using Spearman's rank correlation in Excel. Moreover both PD values of the phallobases and parameres are tested for difference of the PD values of the control groups using a $z$ test for unmatched data using Excel.

\section{Micro-CT scanning}

Micro-CT scans (a new technique considered a powerful tool for the morphological study of insects (Hu et al., 2011)) were made using a SkyScan 1172 scanner (Bruker Daltonics Inc., Bremen, Germany). Aedeagi were scanned for six different species, namely: Cyclocephala amazona (Linnaeus, 1767), C. brittoni Endrödi, 1964, C. cartwrighti Endrödi, 1964, Ruteloryctes morio (Fabricius, 1798), C. castanea (Olivier, 1789) and Peltonotus morio Burmeister, 1847. The latter two were clearly asymmetric. Ideal settings lay between $25 \mathrm{kV}$ to $30 \mathrm{kV}$. Scans were analysed using CTan ver. 1.5.0, CTvol ver. 1.9.4 and CTvox ver. 2.3 (Bruker Daltonics Inc., Bremen, Germany). Photographs and videos were made using CTan ver. 1.5.0. The results obtained with micro-CT scanning were not used in the asymmetry analyses; solely asymmetries visible on conventional photographs were measured.

\section{Results}

The distribution of the PD values of both the parameres and phallobases resulted in a unimodal, positively skewed distribution, with means of 0.037 and 0.022 , respectively. The distributions of the control groups' PD values show a more or less symmetric unimodal distribution with means of 0.0089 for control group 1, the computer-generated objects, and 0.0068 for control group 2, the toothbrushes. Results are shown in Fig. 4. The PD values of both the phallobases and parameres are highly significant different from the PD values of the control groups $(z=9.9, p<0.001$, for phallobases and $z=7.3, p<0.001$, for parameres).

The reweighted heuristic search with 1000 addition sequences resulted in 3 equally optimal trees of 64.57 steps with a consistency index (CI) of 0.567 , homoplasy index (HI) of 0.433 , retention index (RI) of 0.735 , and a rescaled consistency index (RC) of 0.416 . The Cyclocephala complex is highly resolved. In the analyses Cyclocephala is, however, polyphyletic and split into four different groups; all other genera are monophyletic.

Asymmetry data for the parameres and phallobases are plotted on the phylogenetic reconstruction (Fig. 5). Bootstrap values above $70 \%$ provide strong support for clades while not labelled branches have a support of $<65 \%$. The phylogeny shows that 11 species of four genera have asymmetric parameres and six species of four genera have asymmetric phallobases. The minimum number of evolutionary steps for asymmetric parameres is eight while this is six for asymmetric phallobases. Combined, a minimum of nine evolutionary events is necessary, assuming that a symmetric genitalic structure is ancestral. From the total of 119 measured species only nine species show asymmetry in both their parameres and phallobases. Six species show asymmetric phallobases but symmetric parameres, while 28 species show asymmetric parameres but symmetric phallobases.

Micro-CT scans for six species revealed unexpected asymmetric sclerotised structures inside the externally symmetric aedeagus of $C$. amazona. In the remaining five species, the organisation of the interior of the aedeagus followed that of the exterior: a symmetric interior in symmetric genitalia and an asymmetric interior in asymmetric genitalia.

\section{Discussion}

Our observations on the evolutionary patterns of genital asymmetry in this relatively small coleopteran taxon reflects that which was found by Huber et al. (2007) throughout the insects, namely that genital asymmetry is a widespread and common phenomenon and is found scattered over the taxa. In Cyclocephalini, only few species per genus normally have asymmetric aedeagi, however in Peltonotus all species in which males are known, show asymmetric genitalia, although the degree of asymmetry ranges from slight $(\mathrm{PD}=0.0217)$ to extreme $(\mathrm{PD}=0.2763)$. Peltonotus is probably the 


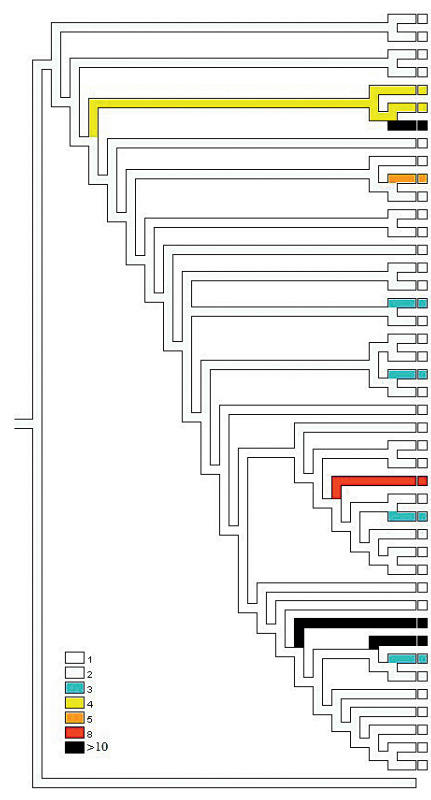

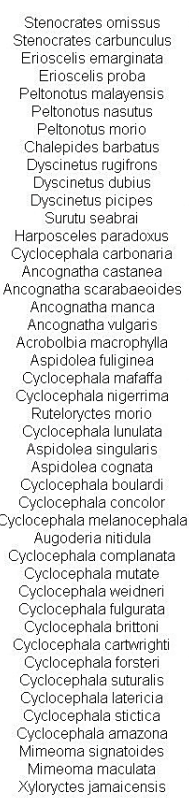

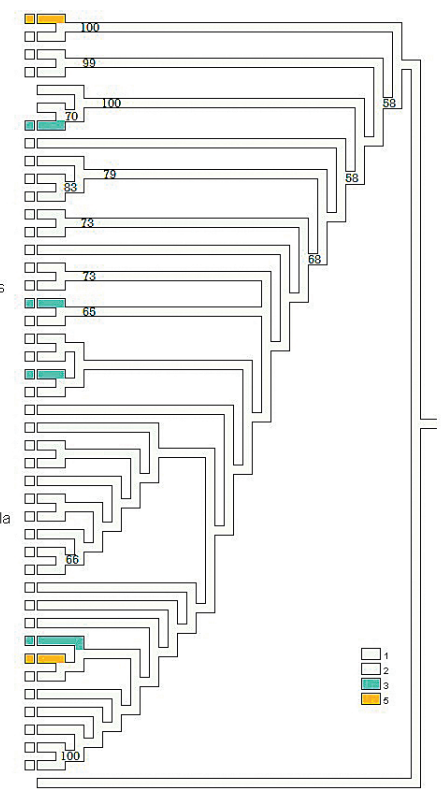

Fig. 5. Phylogenies showing the evolutionary relationships between selected Cyclocephalini taxa with character histories of both the degree of asymmetry of the parameres (left) and the degree of asymmetry of the phallobase (right). Numbers indicate the degree of asymmetry based on Procrustes distances between original and mirrored versions of photographs of the same structure. Procrustes distances are divided in cumulative bins with width of 0.0157 . Both phylogenies are predicted by a strict consensus after successive reweighting based on the rescaled consistency index (RC: 0.416$)$ of the heuristic search with 1000 addition sequences. Bootstrap values (right) based on 50\% majority rule, values greater than $70 \%$ were considered to provide strong support for clades (Felsenstein, 1985), only values $\geq 65 \%$ are given. only genus in the Cyclocephalini, consisting of more than one species, existing solely of asymmetric species. Although our phylogeny is based on a limited sampling of the available taxa, the distribution of asymmetry shown confirms the existence of multiple evolutionary appearances of asymmetry (at least eight times in the parameres and at least six times in the phallobase).

Interestingly, the Cyclocephala species that show asymmetric parameres are placed basally in one of the Cyclocephala clades. More terminally placed Cyclocephala species in this clade are symmetric, suggesting a reversal.

Although for most species, we studied only a single male, in one species (C. amazona) we studied 14 individuals to assess intraspecific variation. The relatively small standard deviations (paramere PD $=0.018$ with SD 0.009, phallobase $\mathrm{PD}=0.018$ with SD 0.007) support the fact that the genitalic structures are more variable between species than they are within species.

The phylogeny shows that the branches in which asymmetric parameres evolve are not necessarily the same as those in which asymmetric phallobases evolve and vice versa. However, there is a moderate positive correlation between asymmetric parameres and asymmetric phallobases in Cyclocephalini and this correlation is highly statistically significant $(r=0.344, p=$ 0.001). A scatterplot (Fig. 6) of the PD values of all measured parameres and phallobases show three distinct groups. One group show increased asymmetry in their phallobase, including Cyclocephala forsteri and
Stenocrates omissus Endrödi, 1966. The other outlier group shows increased asymmetry in their parameres and consists of $C$. brittoni, $C$. boulardi, C. cartwrighti, and all Peltonotus species. The last group consists of most species showing equal (a)symmetry in their phallobase and parameres. The range of PD values of the parameres is more than twice as broad as that of phallobases. Parameres tend to be more 'extremely' asymmetric than phallobases, suggesting that asymmetries

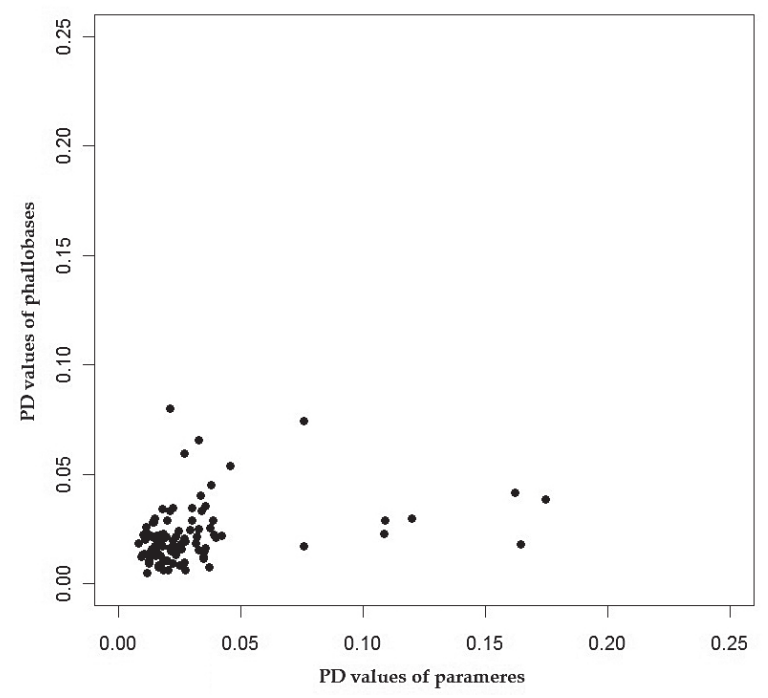

Fig. 6. Scatterplot of Procrustes distance values of both the phallobase and parameres. 

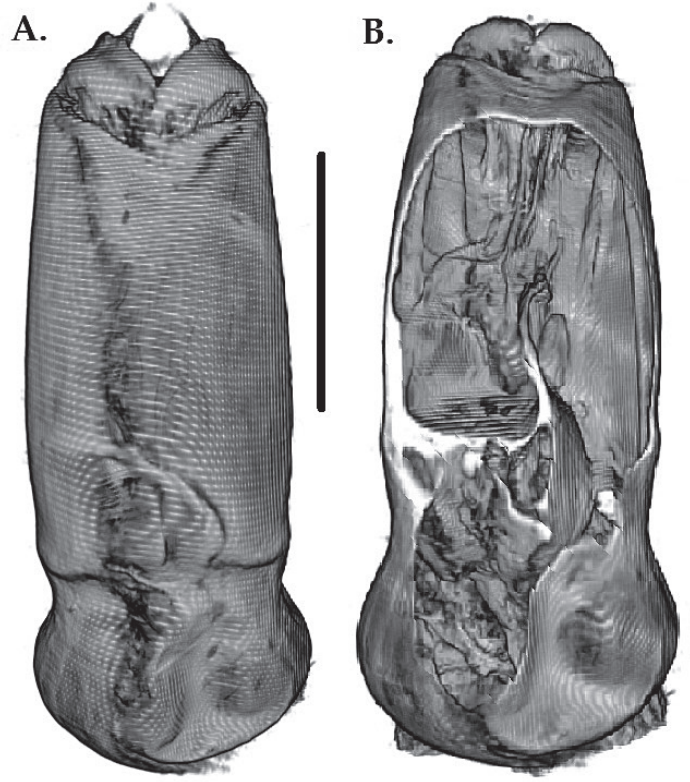

Fig. 7. Micro CT-scans of A, B, and C phallobase of $C$. amazona with symmetric outside structure (A) but an asymmetric interior (B and C). Procrustes distance values were 0.0122 for parameres and 0.0223 for phallobase (scale bar $=1 \mathrm{~mm}$ ). develop primarily at the terminal part of the aedeagus. During mating the parameres enter the female's reproductive tract while the phallobase is not inserted (Werner and Simmons, 2008; pers. obs. of micro-CT scans of a preserved copula). Possibly, selection for asymmetry acts more strongly on the structures actually interacting with the female's reproductive system, i.e., the parameres. Another explanation for asymmetries at the terminal part is the fact that purifying selection acting on the aedeagus may be stronger on the phallobase which is connected to erectile muscles.

The histograms that show the range of PD values for parameres and phallobases (Fig. $4 \mathrm{~B}$ and C) display unimodal, positively skewed distributions. This shows that there is no clear separation into either symmetric or asymmetric structures: the symmetric aedeagi grade smoothly into asymmetric forms ending in a long tail of extremely asymmetric parameres. This is an interesting result, since it conflicts with the idea that, in the evolution of asymmetry, an adaptive valley needs to be crossed that is due to sexual selection for reduced fluctuating asymmetry. Apparently, if such an adaptive valley exists, it is very narrow.

Our micro-CT scans show that in at least one species, C. amazona, asymmetric sclerotized structures exist in the interior of the symmetric phallobase (Fig. 7), suggesting that more morphological asymmetries might lie hidden within otherwise symmetric aedeagi in this group. These sclerotised structures appear not to be artifactual structures attached to the membranous en- dophallus, but instead appear to be connected to the sides of the phallobase while the endophallus is shrunken.

Although much is already known about genitalic anatomy of Scarabaeoidae (Tarasov and Solodovnikov, 2011; Zunino, 2012), micro-CT scanning could contribute in this field of research. Given the interesting results obtained with micro-CT scanning of a small number of individuals, we advocate that in future studies this type of research could be extended to a larger scale where several tribes or several (sub)families are analyzed. Furthermore, we hope future molecular studies may improve and expand the phylogenetic reconstruction upon which our genital asymmetry data can be projected. Finally, Micro-CT scanning should get a leading role in future researches. It could be combined with mating experiments where mating insects are studied to compare the mating strategies of species with asymmetric versus those with symmetric genitalia. These types of studies can be carried out in a similar manner as Werner and Simmons (2008) did, using freeze spray to fixate beetles during mating.

This kind of morphological studies may allow further interpretation of morphological and phylogenetic patterns in reference to the six hypotheses posited by Huber et al. (2007; see Introduction). The phylogenetic patterns in male genital asymmetry in the Cyclocephalini suggests that asymmetry has evolved repeatedly, in a group for which no major shifts in mating position are known. Therefore, the hypothesis of mechanical com- 
pensation is not likely to have high explanatory power in this case. However, to determine which of the five alternative hypotheses is supported, details of copulatory mechanics and, perhaps even more importantly, of (a)symmetry in the female genitalia are needed. Once these become available, a comprehensive analysis of the causes of genital asymmetry in this taxon will become possible. Such analyses are important not only because they can change our view on the role of symmetry in sexual selection (van Dongen, 2006) but also because they may have a bearing on understanding congenital symmetry defects in other organisms, including humans (Bots et al., 2011; Schilthuizen and Gravendeel, 2012; Schilthuizen, 2013).

\section{Acknowledgements}

We want to thank Eulalia Gassó Miracle, Fred van Assen and Ben Brugge (Naturalis Biodiversity Center), as well as M.L. Jameson (Wichita State University), M. Gibernau (CNRS Ecofog, France), B.C. Ratcliffe (University of Nebraska) and all other researchers and students who have helped us in one or another way during this research. Further we want to thank three anonymous reviewers who helped us to improve the final manuscript. This project was supported by a Naturalis research grant for the focus group Character Evolution.

\section{References}

Bots J, Wijnaendts LCD, Delen S, Dongen S van, Heikinheimo $\mathrm{K}$, Galis F. 2011. Analysis of cervical ribs in a series of human fetuses. Journal of Anatomy 219: 403-409.

Clark DR. 2011. Phylogenetic analysis of the scarab beetle tribe Cyclocephalini (Coleoptera: Scarabaeidae: Dynastinae) based on adult morphological characters. Unpublished thesis Wichita University. Available at: http://soar.wichita.edu/ dspacce/handle/10057/5050 [accessed June 2012].

Dongen S van. 2006. Fluctuating asymmetry and developmental instability in evolutionary biology: past, present and future. Journal of Evolutionary Biology 19: 1727-1743.

Eberhard WG. 1985. Sexual Selection and Animal Genitalia. Cambridge, Massachusetts: Harvard University Press.

Eberhard WG. 2004. Rapid divergent evolution of sexual morphology: comparative tests of antagonistic coevolution and traditional female choice. Evolution 58: 1947-1970.

Eberhard WG. 2006. Sexually antagonistic coevolution in insects is associated with only limited morphological diversity. Journal of Evolutionary Biology 19: 657-681.

Eberhard WG. 2010. Evolution of genitalia: theories, evidence, and new directions. Genetica 138: 5-18.

Endrödi S. 1985. The Dynastinae of the World. The Hague: Junk.

Felsenstein J. 1985. Confidence limits on phylogenies: an approach using the bootstrap. Evolution 39: 783-791.

Gage MJG. 1992. Removal of rival sperm during copulation in a beetle, Tenebrio molitor. Behavioral Ecology 44: 587-589.
Gibernau M, Barabe D, Cerdan P, Dejean A. 1999. Beetle pollination of Philodendron solimoesense (Araceae) in French Guiana. International Journal of Plant Sciences 160: 1135-1143.

Hu Z, Gui J, Zou J, Rong J, Zhang Q, Zheng H, Xia D. 2011. Geometric calibration of a Micro-CT system and performance for insect imaging. IEEE Transactions on Information Technology in Biomedicine 15: 655-660.

Huber BA, Sinclair BJ, Schmitt M. 2007. The evolution of asymmetric genitalia in spiders and insects. Biological Reviews 82: 647-698.

Jameson ML, Ratcliffe BC, Maly V. 2002. Review of the genus Acrobolbia with remarks on its classification, and a key to the world genera of Cyclocephalini (Coleoptera: Scarabaeidae: Dynastinae). Folia Heyrovskyana 10: 1-15.

Jameson ML, Wada K. 2004. Revision of the genus Peltonotus Burmeister (Coleoptera: Scarabaeidae: Dynastinae) from Southeastern Asia. Zootaxa 502: 1-66.

Jameson ML, Wada K. 2009. Five new species of Peltonotus Burmeister (Scarabaeidae: Dynastinae: Cyclocephalini) from Southeast Asia. Insecta Mundi 102: 1-16.

Krell FT,Gunnar H, Seine R, Porembski S. 2003. Rhinoceros beetles pollinate water lilies in Africa (Coleoptera: Scarabaeidae: Dynastinae; Magnoliidae: Nymphaeaceae). Ecotropica 9: 103-106.

Leonard JL, Córdoba-Aguilar A. 2010. The Evolution of Primary Sexual Characters in Animals. Oxford: Oxford University Press.

Maddison WP, Maddison RD. 2011. Mesquite: A modular system for evolutionary analysis, version 2.75. Available at: http:// www.mesquiteproject.org [accessed April 2012].

Møller AP, Pomiankowski A. 1993. Fluctuating asymmetry and sexual selection. Genetica 89: 267-279.

Parker GA. 1970. Sperm competition and its evolutionary consequences in the insects. Biological Reviews 45: 525-567.

R Development Core Team. 2010. R: A language and environment for statistical computing. R Foundation for Statistical Computing, Vienna, Austria. Available at: http://www.R-projects.org.

Ratcliffe BC, Cave RD. 2008. The Dynastinae (Coleoptera: Scarabaeidae) of the Bahamas with a description of a new species of Cyclocephala from Great Inagua Island. Insecta Mundi 24: 1-10.

Ratcliffe BC, Paulsen MJ. 2008. The scarabaeoid beetles of Nebraska. Bulletin of the University of Nebraska State Museum 22: 1-569.

Rohlf FJ. 2010. tpsDig, digitize landmarks and outlines, version 2.16. Department of Ecology and Evolution, State University of New York at Stony Brook, NJ. Available at: http://life.bio. sunysb.edu/morph/ [accessed February 2012].

Schilthuizen M. 2003. Shape matters: the evolution of insect genitalia. Proceedings of the Section applied and experimental Entomology of the Netherlands Entomological Society 14: 9-15.

Schilthuizen M. 2013. Something gone awry: unsolved mysteries in the evolution of asymmetric animal genitalia. Animal Biology 63: 1-20.

Schilthuizen M, Gravendeel B. 2012. Left-right asymmetry in plants and animals: a gold mine for research. Contributions to Zoology 81: 75-78.

Sheets HD. 2011. IMP, Integrated Morphometrics Package. Department of Physics, Canisius College, Buffalo, NY. Available at: http://www.canisius.edu/ sheets/morphsoft.html [accessed April 2012]. 
Swaddle JP, Cuthill IC. 1994. Preference for symmetric males by female zebra finches. Nature 367: 165-166.

Swofford DL. 2001. PAUP: phylogenetic analysis using parsimony, version 4.0b10. Laboratory of Molecular Systematics Museum Support Center Smithsonian Institution Washington, DC. Available at: http://paup.csit.fsu.edu/ [accessed October 2011].

Tarasov SI, Solodovnikov AY. 2011. Phylogenetic analyses reveal reliable morphological markers to classify mega-diversity in Onthophagini dung beetles (Coleoptera: Scarabaeidae: Scarabaeinae). Cladistics 27: 1-39.

Werner M, Simmons LW. 2008. The evolution of male genitalia: functional integration of genital sclerites in the dung beetle
Onthophagus taurus. Biological Journal of the Linnean Society 93: 257-266.

Zunino M. 2012. Forty years of genital anatomy in Scarab Beetles (Coleoptera: Scarabaeoidae) taxonomy: the state of the art. Dugesiana 18: 197-206.

Received: 19 December 2012

Revised and accepted: 25 April 2013

Published online: 14 June 2013

Editor: J.W. Arntzen 


\section{Appendix}

Material studied. Given are: species name, author, Procrustes distance (PD) of both the parameres (top) and phallobase (base), character states (CS) of PD values (see main text), and basic collection information is given. Asterisks $(*)$ denote taxa included in the phylogenetic analyses. A hashtag (\#) denotes taxa analyzed using photographs from literature. ID = Indonesia, MAS $=$ Malaysia, $\mathrm{n} / \mathrm{a}=$ not applicable.

\begin{tabular}{|c|c|c|c|c|c|c|c|}
\hline Species & Author & PD top & PD base & CS top & CS base & Country & Date \\
\hline Acrobolbia macrophylla \#* & Ohaus, 1912 & 0.0228 & 0.0157 & 2 & 1 & Peru & 1980-1981 \\
\hline Ancognatha castanea* & (Erichson, 1847) & 0.0298 & 0.0289 & 2 & 2 & Ecuador & iii-1981 \\
\hline A. erythrodera & (Blanchard, 1846) & 0.0333 & 0.0404 & 3 & 3 & Bolivia & ? \\
\hline A. humeralis & Burmeister, 1847 & 0.0145 & 0.0162 & 1 & 2 & Colombia & $?$ \\
\hline A. manca* & LeConte, 1866 & 0.0377 & 0.0449 & 3 & 3 & Mexico & $?$ \\
\hline A. scarabaeoides* & Erichson, 1847 & 0.0172 & 0.0194 & 2 & 2 & Peru & $?$ \\
\hline A. ustulata & Burmeister, 1847 & 0.0319 & 0.0214 & 2 & 2 & Colombia & ? \\
\hline A. vulgaris* & Arrow, 1911 & 0.0183 & 0.0227 & 2 & 2 & Colombia & 23-i-1976 \\
\hline Aspidolea boulardi* & Dechambre, 1979 & 0.1198 & 0.0300 & 8 & 2 & Suriname & 26-v-1981 \\
\hline A. cognata* & Höhne, 1922 & 0.0198 & 0.0104 & 2 & 1 & Venezuela & 22-xi-1968 \\
\hline A.fuliginea* & Burmeister, 1847 & 0.0143 & 0.0279 & 1 & 2 & Panama & 21-iii-1983 \\
\hline A. singularis* & Bates, 1888 & 0.0117 & 0.0047 & 1 & 1 & Ecuador & 8-iv-1983 \\
\hline Augoderia nitidula* & Burmeister, 1847 & 0.0213 & 0.0150 & 2 & 1 & Brazil & ? \\
\hline Chalepides barbatus* & (Fabricius, 1787) & 0.0221 & 0.0199 & 2 & 2 & Argentina & 12-vii-1924 \\
\hline Cyclocephala amazona* & (Linnaeus, 1767) & 0.0122 & 0.0223 & 1 & 2 & Suriname & iv-1973 \\
\hline C.atricapilla & Mannerheim, 1829 & 0.0267 & 0.0204 & 2 & 2 & Brazil & xi-1953 \\
\hline C. atricolor & Chapin, 1932 & 0.0161 & 0.0086 & 2 & 1 & Cuba? & iii-1939 \\
\hline C. bicolor & Castelnau, 1840 & 0.0420 & 0.0219 & 3 & 2 & Guyana & iii-1992 \\
\hline C. brittoni* ${ }^{*}$ & Endrödi, 1964 & 0.1644 & 0.0182 & 11 & 2 & Brazil & $10-$ vi-1978 \\
\hline C. carbonaria* & Arrow, 1911 & 0.0198 & 0.0290 & 2 & 2 & Ecuador & ii-1997 \\
\hline C.cardini & Chapin, 1935 & 0.0253 & 0.0181 & 2 & 2 & Cuba? & ? \\
\hline C. cartwrighti* & Endrödi, 1964 & 0.1622 & 0.0415 & 11 & 3 & Panama & ? \\
\hline C. castanea & (Olivier, 1789) & 0.0177 & 0.0343 & 2 & 3 & Suriname & 19-vii-1975 \\
\hline C.cearae & Höhne, 1923 & 0.0258 & 0.0158 & 2 & 2 & Brazil & xi-1952 \\
\hline C. colasi & Endrödi, 1964 & 0.0293 & 0.0247 & 2 & 2 & Suriname & 6-iii-1978 \\
\hline C. complanata* & Burmeister, 1847 & 0.0165 & 0.0218 & 2 & 2 & Mexico & ? \\
\hline C. concolor* & Burmeister, 1847 & 0.0154 & 0.0197 & 1 & 2 & Mexico & 22-viii-1976 \\
\hline C. contracta & Kirsch, 1873 & 0.0166 & 0.0078 & 2 & 1 & Bolivia & xii-1956 \\
\hline C.crepuscularis & Martinez, 1945 & 0.0300 & 0.0347 & 2 & 3 & Argentina & 12-vii-1924 \\
\hline C. curta & Bates, 1888 & 0.0171 & 0.0200 & 2 & 2 & San Salvador & v-1953 \\
\hline C. diluta & Erichson, 1847 & 0.0178 & 0.0173 & 2 & 2 & Fr. Guyana & 17-viii-1996 \\
\hline C. discolor & (Herbst, 1792) & 0.0149 & 0.0128 & 1 & 1 & Trinidad & 26-vii-1929 \\
\hline C.fankhaeneli & Endrödi, 1964 & 0.0170 & 0.0080 & 2 & 1 & Brazil & xii-1941 \\
\hline C. fasciolata & Bates, 1888 & 0.0220 & 0.0345 & 2 & 3 & Mexico & 13-viii-1988 \\
\hline C. forsteri* ${ }^{*}$ & Endrödi, 1963 & 0.0326 & 0.0655 & 3 & 5 & Brazil & iv-1954 \\
\hline C. fulgurata* & Burmeister, 1847 & 0.0134 & 0.0214 & 1 & 2 & Trinidad & 19-iv-1969 \\
\hline C. gregaria & $\begin{array}{l}\text { Heyne and } \\
\text { Taschenberg, } 1907\end{array}$ & 0.0134 & 0.0158 & 1 & 2 & Colombia & ? \\
\hline C. hirta & LeConte, 1861 & 0.0124 & 0.0093 & 1 & 1 & USA & ? \\
\hline C. immaculata & (Olivier, 1789) & 0.0139 & 0.0279 & 1 & 2 & USA & 23-vi-1961 \\
\hline C. laminata & Burmeister, 1847 & 0.0147 & 0.0299 & 1 & 2 & Suriname & iiii-73 \\
\hline C. latericia* & Höhne, 1923 & 0.0270 & 0.0096 & 2 & 1 & Argentina & ii-1973 \\
\hline C. literata & Burmeister, 1847 & 0.0163 & 0.0073 & 2 & 1 & Brazil & 1977 \\
\hline C. longula & LeConte, 1863 & 0.0375 & 0.0253 & 3 & 2 & USA & vi-1951 \\
\hline C. lunulata* & Burmeister, 1847 & 0.0183 & 0.0060 & 2 & 1 & Suriname & 7-viii-1961 \\
\hline C.lutea & Endrödi, 1966 & 0.0396 & 0.0210 & 3 & 2 & Argentina & ? \\
\hline C. mafaffa* & Burmeister, 1847 & 0.0340 & 0.0332 & 3 & 3 & Peru & 1938 \\
\hline C. mecynotarsis & Höhne, 1923 & 0.0371 & 0.0076 & 3 & 1 & Brazil & ii-1962 \\
\hline C. melanocephala* & (Fabricius, 1775) & 0.0354 & 0.0163 & 3 & 2 & San Salvador & 5-iii-1956 \\
\hline
\end{tabular}


cont.

\begin{tabular}{|c|c|c|c|c|c|c|c|}
\hline Species & Author & PD top & PD base & CS top & CS base & Country & Date \\
\hline C.metrica & Steinheil, 1874 & 0.0122 & 0.0106 & 1 & 1 & Argentina & 12-vii-1924 \\
\hline C. minuta & Burmeister, 1847 & 0.0353 & 0.0356 & 3 & 3 & Guyana & 25-ix-1989 \\
\hline C.modesta & Burmeister, 1847 & 0.0327 & 0.0249 & 3 & 2 & Argentina & 12-vii-1924 \\
\hline C. nigerrima* & Bates, 1888 & 0.0246 & 0.0243 & 2 & 2 & Costa Rica & 9-xii-1980 \\
\hline C. notata & (Illiger, 1806) & 0.0247 & 0.0085 & 2 & 1 & St. Domingo & ? \\
\hline C.obesa & Burmeister, 1847 & 0.0183 & 0.0101 & 2 & 1 & Trinidad & 26-vii-1929 \\
\hline C.occipitalis & Fairmare, 1892 & 0.0170 & 0.0223 & 2 & 2 & Antilles & ? \\
\hline C. paraguayensis & Arrow, 1913 & 0.0246 & 0.0155 & 2 & 1 & Paraguay & 5-xi-1991 \\
\hline C.parallela & Casey, 1915 & 0.0352 & 0.0150 & 3 & 1 & USA: Florida & vi-1966 \\
\hline C.pasadenae & Casey, 1915 & 0.0153 & 0.0219 & 1 & 2 & USA & 22-vii-1964 \\
\hline C.perforata & Arrow, 1911 & 0.0202 & 0.0063 & 2 & 1 & Suriname & 10-xi-1981 \\
\hline C. picta & Burmeister, 1847 & damaged & 0.0214 & & 2 & Mexico & ? \\
\hline C.pilosicollis & Saylor, 1936 & 0.0389 & 0.0224 & 3 & 2 & USA & 21-iv-1961 \\
\hline C.pubescens & Burmeister, 1847 & 0.0170 & 0.0193 & 2 & 2 & Colombia & v-1983 \\
\hline C.pugnax & Arrow, 1914 & 0.0316 & 0.0186 & 2 & 2 & Colombia & vi-1983 \\
\hline C.putrida & Burmeister, 1847 & 0.0272 & 0.0062 & 2 & 1 & Argentina & 12-ii-1973 \\
\hline C. quatuordecimpunctata & Mannerheim, 1829 & 0.0082 & 0.0185 & 1 & 2 & Bolivia & xi-1975 \\
\hline C. rubescens & Bates, 1891 & 0.0197 & damaged & 2 & & Ecuador & ii-1997 \\
\hline C.rustica & (Olivier, 1789) & 0.0107 & 0.0202 & 1 & 2 & Suriname & 23-v-1981 \\
\hline C. mutata* ab. of & Burmeister, 1847 & 0.0103 & 0.0135 & 1 & 1 & Brazil & ? \\
\hline \multicolumn{8}{|l|}{ C. sanguinicollis } \\
\hline C. sexpunctata & Castelnau, 1840 & 0.0347 & 0.0115 & 3 & 1 & Panama & $30-v i-1976$ \\
\hline C. signaticollis & Burmeister, 1847 & 0.0186 & 0.0106 & 2 & 1 & Mexico & ? \\
\hline C. simulatrix & Höhne, 1923 & 0.0211 & 0.0163 & 3 & 2 & Suriname & $18-\mathrm{v}-1981$ \\
\hline C. sinuosa & Höhne, 1923 & 0.0348 & 0.0123 & 3 & 1 & Suriname & ? \\
\hline C. stictica* & Burmeister, 1847 & 0.0271 & 0.0194 & 2 & 2 & Bolivia & $x-1949$ \\
\hline C. suturalis* & Ohaus, 1911 & 0.0194 & 0.0213 & 2 & 2 & Brazil & ? \\
\hline C.testacea & Burmeister, 1847 & 0.0455 & 0.0538 & 3 & 4 & Suriname & xii-1961 \\
\hline C. tridentata & (Fabricius, 1801) & 0.0233 & 0.0132 & 2 & 1 & St. Dominica & $30-v-1965$ \\
\hline C.tucumana & Bréthes, 1904 & 0.1086 & 0.0227 & 7 & 2 & Argentina & i-1951 \\
\hline C.tutilina & Burmeister, 1847 & 0.0231 & 0.0216 & 2 & 2 & Colombia & $?$ \\
\hline C. variabilis & Burmeister, 1847 & 0.0097 & 0.0131 & 1 & 1 & Argentina & ? \\
\hline C.verticalis & Burmeister, 1847 & 0.0091 & 0.0124 & 1 & 1 & Suriname & 28-vii-1975 \\
\hline C.vestita & Höhne, 1923 & 0.0268 & 0.0594 & 2 & 4 & Brazil & 17-xii-1979 \\
\hline C.weidneri* & Endrödi, 1964 & 0.0101 & 0.0224 & 1 & 2 & Venezuela & 18-v-1980 \\
\hline Dyscinetus dubius* & (Olivier, 1789) & 0.0758 & 0.0170 & 5 & 2 & Brazil & 2-xii-1988 \\
\hline D. gagates & (Burmeister, 1847) & 0.0387 & 0.0290 & 3 & 2 & Argentina & ? \\
\hline D. olivaceus & Höhne, 1923 & 0.0222 & 0.0094 & 2 & 1 & Brazil & 11-xi-1985 \\
\hline D. picipes* & (Burmeister, 1847) & 0.0328 & 0.0155 & 2 & 1 & Brazil & ? \\
\hline D. rugifrons* & (Burmeister, 1847) & 0.1090 & 0.0291 & 1 & 2 & Argentina & ? \\
\hline Erioscelis emarginata* & (Mannerheim, 1829) & 0.0167 & 0.0195 & 2 & 2 & Brazil & ? \\
\hline E.proba* & Sharp, 1877 & 0.0171 & 0.0126 & 2 & 1 & Peru & ? \\
\hline Harposceles paradoxus* & Burmeister, 1847 & 0.0157 & 0.0130 & 1 & 1 & Fr. Guyana & xii-1990 \\
\hline Mimeoma maculata* & Burmeister, 1847 & 0.0156 & 0.0147 & 1 & 1 & Suriname & 25-v-1981 \\
\hline M. signatoides* & Höhne, 1923 & 0.0110 & 0.0257 & 1 & 2 & Suriname & $26-\mathrm{v}-1981$ \\
\hline Peltonotus adelphosimilis \# & Jameson and Wada, 2004 & 0.2558 & $\mathrm{n} / \mathrm{a}$ & 17 & $\mathrm{n} / \mathrm{a}$ & ID: Borneo & X-1990 \\
\hline P. animus \# & Jameson and Wada, 2009 & 0.0254 & $\mathrm{n} / \mathrm{a}$ & 2 & $\mathrm{n} / \mathrm{a}$ & ID: Sumatra & ? \\
\hline P. brunnipennis \# & Benderitter, 1934 & 0.0271 & $\mathrm{n} / \mathrm{a}$ & 2 & $\mathrm{n} / \mathrm{a}$ & MAS: Borneo & $?$ \\
\hline P.cybele \# & Jameson and Wada, 2009 & 0.1352 & $\mathrm{n} / \mathrm{a}$ & 9 & $\mathrm{n} / \mathrm{a}$ & ID: Sumatra & $?$ \\
\hline P. deltamentum \# & Jameson and Wada, 2004 & 0.0499 & $\mathrm{n} / \mathrm{a}$ & 4 & $\mathrm{n} / \mathrm{a}$ & ID: Borneo & $x-1989$ \\
\hline P.favonius \# & Jameson and Wada, 2009 & 0.0647 & $\mathrm{n} / \mathrm{a}$ & 4 & $\mathrm{n} / \mathrm{a}$ & $?$ & ? \\
\hline P. fujiokai \# & Jameson and Wada, 2004 & 0.0217 & $\mathrm{n} / \mathrm{a}$ & 2 & $\mathrm{n} / \mathrm{a}$ & ID: Borneo & vi-1990 \\
\hline P. gracilipodus \# & Jameson and Wada, 2004 & 0.0449 & $\mathrm{n} / \mathrm{a}$ & 3 & $\mathrm{n} / \mathrm{a}$ & ID: Sumatra & x-1987 \\
\hline P. karubei \# & Muramoto, 2000 & 0.0622 & $\mathrm{n} / \mathrm{a}$ & 4 & $\mathrm{n} / \mathrm{a}$ & Vietnam & 2000 \\
\hline P. malayensis \#* & Arrow, 1910 & 0.0504 & $\mathrm{n} / \mathrm{a}$ & 4 & $\mathrm{n} / \mathrm{a}$ & Borneo & ? \\
\hline P. morio* & Burmeister, 1847 & 0.1746 & 0.0386 & 12 & 3 & British Bootang & 1899 \\
\hline P. nasutus \#* & Arrow, 1910 & 0.0553 & $\mathrm{n} / \mathrm{a}$ & 4 & $\mathrm{n} / \mathrm{a}$ & $?$ & $?$ \\
\hline
\end{tabular}


cont.

\begin{tabular}{|c|c|c|c|c|c|c|c|}
\hline Species & Author & PD top & PD base & CS top & CS base & Country & Date \\
\hline P.podocrassus \# & Jameson and Wada, 2004 & 0.0367 & $\mathrm{n} / \mathrm{a}$ & 3 & $\mathrm{n} / \mathrm{a}$ & Malaysia & 29-iv-1984 \\
\hline P. rubripennis \# & Miyake and Yamaya, 1994 & 0.0521 & $\mathrm{n} / \mathrm{a}$ & 4 & $\mathrm{n} / \mathrm{a}$ & MAS: Borneo & ? \\
\hline P. silvanus \# & Jameson and Wada, 2004 & 0.0271 & $\mathrm{n} / \mathrm{a}$ & 2 & $\mathrm{n} / \mathrm{a}$ & MAS: Borneo & v-1988 \\
\hline P. similis \# & Arrow, 1931 & 0.2763 & $\mathrm{n} / \mathrm{a}$ & 18 & $\mathrm{n} / \mathrm{a}$ & MAS: Borneo & ? \\
\hline P. sisyrus \# & Jameson and Wada, 2004 & 0.0778 & $\mathrm{n} / \mathrm{a}$ & 5 & $\mathrm{n} / \mathrm{a}$ & ID: Sumatra & 1993 \\
\hline P. talangensis \# & Jameson and Jakl, 2010 & 0.0263 & $\mathrm{n} / \mathrm{a}$ & 2 & $\mathrm{n} / \mathrm{a}$ & ID: Sumatra & ii-2006 \\
\hline P. vittatus \# & Arrow, 1910 & 0.0251 & $\mathrm{n} / \mathrm{a}$ & 2 & $\mathrm{n} / \mathrm{a}$ & MAS: Borneo & ? \\
\hline Ruteloryctes morio* & (Fabricius, 1798) & 0.0145 & 0.0172 & 1 & 2 & Liberia & 1881 \\
\hline Stenocrates carbo & Prell, 1938 & 0.0222 & damaged & 2 & & Brazil & 11-xi-1985 \\
\hline S. carbunculus* & Prell, 1938 & 0.0234 & 0.0161 & 2 & 2 & Brazil & 29-ix-1971 \\
\hline S.cognatus & Endrödi, 1966 & 0.0210 & 0.0333 & 2 & 3 & Trinidad & i-1973 \\
\hline S. holomelanus & (Germar, 1824) & 0.0757 & 0.0745 & 5 & 5 & Guyana & 18-ix-1989 \\
\hline S.s inelegans & Arrow, 1913 & 0.0181 & 0.0207 & 2 & 2 & Brazil & ? \\
\hline S.omissus* & Endrödi, 1966 & 0.0210 & 0.0800 & 2 & 5 & Peru & 22-vi-1908 \\
\hline Surutu seabrai* & $\begin{array}{l}\text { Andretta and } \\
\text { Martinez, } 1956\end{array}$ & 0.0126 & 0.0141 & 1 & 1 & Brazil & i-1977 \\
\hline
\end{tabular}

